\title{
Multiphysics Study of Tensile Testing using Infrared thermography
}

\author{
E Stange', Z Andleeb², H Khawaja1*, \\ M Moatamedi ${ }^{3}$ \\ 1. UiT-The Arctic University of Norway \\ 2. Ghulam Ishaq Khan Institute of Engineering Sciences and \\ Technology, Pakistan \\ 3. Oslo Metropolitan University, Norway
}

\begin{abstract}
In this work, the IR thermography was used to study the steel specimens (DIN 50125 Standard) undergoing the tensile tests. The tensile tests were performed using GUNT ${ }^{\circledR}$ Hamburg Universal Material Tester. The tensile specimens were clamped, and the test force was generated using a handoperated hydraulic system. A dial gauge measured the elongation of the specimens. Using the WP 300.20 system for data acquisition, the measured values for force and displacement were recorded in a PC. The IR thermographic imaging was performed using the FLIR ${ }^{\circledR} T 1030$ sc IR camera and ResearchIR Max software. The steel specimens were coated with high emissivity paint. Thermography revealed that the steel specimens show noticeable thermal signature when undergoing tensile loading. The samples were found to be warmer by $20-25^{\circ} \mathrm{C}$ at the time of failure. The tests were repeated under various surrounding temperatures such as $25^{\circ} \mathrm{C},-5^{\circ} \mathrm{C},-10$ ${ }^{\circ} \mathrm{C},-15^{\circ} \mathrm{C}$, and $-20^{\circ} \mathrm{C}$. The same study was compared with the finite element numerical simulation in ANSYS $^{\circledR}$ Workbench. The experimental and simulation results were found to be in a qualitative agreement.
\end{abstract}

\section{INTRODUCTION}

The uniaxial tensile test is one of the most fundamental types of material characterization test available. It works by continuously measuring the force required to elongate a test specimen by increasing increments until it fractures. The destructive test process measures a number of important material properties i.e. elasticity, plasticity, ultimate strength and maximum elongation of the material. Most importantly, it generates stress strain curve, which is a graphical measure of a material's mechanical properties. The curves are the unique identifiers of each material tested (material's DNA) [1].

Infrared (IR) refers to a band of electromagnetic waves between the $1 \mathrm{~mm}$ (frequency of $300 \mathrm{GHz}$ ) to $0.7 \mu \mathrm{m}$ wavelengths (frequency of $430 \mathrm{THz}$ ) and photon energy from $1.24 \mathrm{meV}$ to $1.7 \mathrm{eV}$. Thermal radiation is generated due to the interatomic motion of the particles. It happens in any matter above absolute zero (zero degrees Kelvin) [2]. By using thermal imaging camera, the infrared wavelengths emitted from the test specimen can be observed in high-definition thermal images. The rate of energy emitted as thermal radiation is highly dependent on the surface temperature. IR detection devices such as IR cameras scan over a range of wavelengths and average over the results to calculate the IR signature [3].

*Corresponding Author: hassan.a.khawaja@uit.no 
Finite element analysis has emerged as one of the most popular technique for studying engineering structures in detail. It is particularly useful whenever the complexity of the geometry or of the loading is such that alternative methods are inappropriate. The finite element method is based on the principle that a complex structure can be broken down into a finite number of smaller elements, the behavior of each element is known or can be postulated. These elements might then be assembled, in some sense, to model the behavior of the structure [4]. However, it is clear that the finite element method is an extremely powerful tool for the analysis of structures (and for other field problems), but the volume of calculations essentially requires the assistance of a computer. Researchers have used finite element method to study various engineering problems [5-9].

\section{METHODOLOGY}

The tensile tests were conducted with the intentions of generating stress-strain diagrams and thermographic images of the DIN 50125 standard steel specimens [10]. These tests were performed under various temperature conditions $25^{\circ} \mathrm{C},-5{ }^{\circ} \mathrm{C},-10{ }^{\circ} \mathrm{C},-15{ }^{\circ} \mathrm{C}$, and $-20{ }^{\circ} \mathrm{C}$. The tensile tests were repeated multiple times to ensure that repeatability of the results. A numerical analysis with the finite element simulation method, using ANSYS ${ }^{\circledR}$ Workbench software $[11,12]$ was conducted for qualitative comparison with the physical experiments.

\subsection{GUNT® Hamburg Universal Material Tester}

The GUNT ${ }^{\circledR}$ Hamburg universal material tester [13], displayed in Figure 1, was used to carry out all the experimental tensile tests in this study. The tensile specimens are clamped between the upper cross member and the crosshead. The test force is generated by means of a hand-operated hydraulic system and displayed on a large force gauge with the pressure indicator. A dial gauge measures the elongation of the specimens.

The tensile tests were first carried out in room temperature $\left(25^{\circ} \mathrm{C}\right)$, thereafter, the Universal Material Tester was moved into the cold room. The cold room was used for exposure of the tensile tests to low temperatures. For each defined temperature, the tensile test was carried out multiple times, in order to lower the uncertainties of the measurement results. Before the test both the test specimens and the material tester were given sufficient time in the cold room at the defined temperatures to achieve the equivalent temperatures.

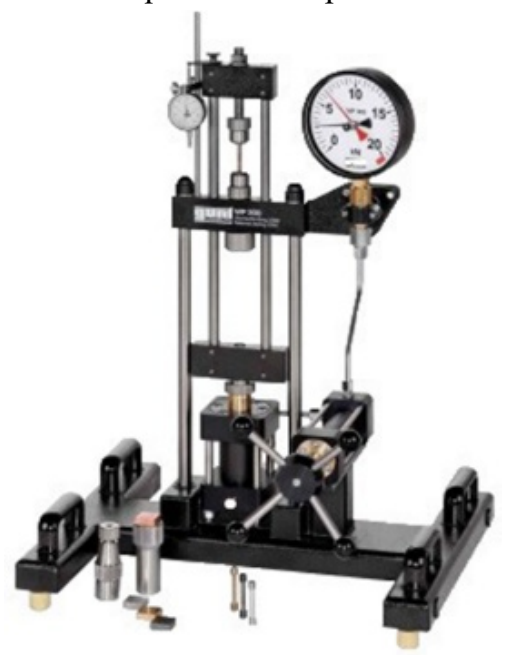

Figure 1: GUNT® Hamburg Universal Material Tester 


\subsection{DIN 50125 Standard Steel Test Specimens}

The test specimens used were DIN 50125 standard steel [10]. The steel specimen has a circular cross-section, with two center punch marks on the shafts to mark the test length, as shown in Figure 2 .

Figure 2: Test Specimen

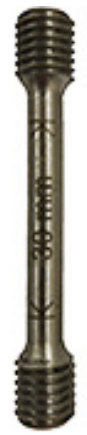

\subsection{Data Acquisition}

The universal material tester used was equipped with an electronic measuring system. By using this system, measured values for force and displacement can be transferred to a computer and analyzed with the system software (Figure 3). Measured values are evaluated in the user-friendly software, so stress-strain diagrams can be recorded. The raw data was exported and stored for all tensile tests performed.

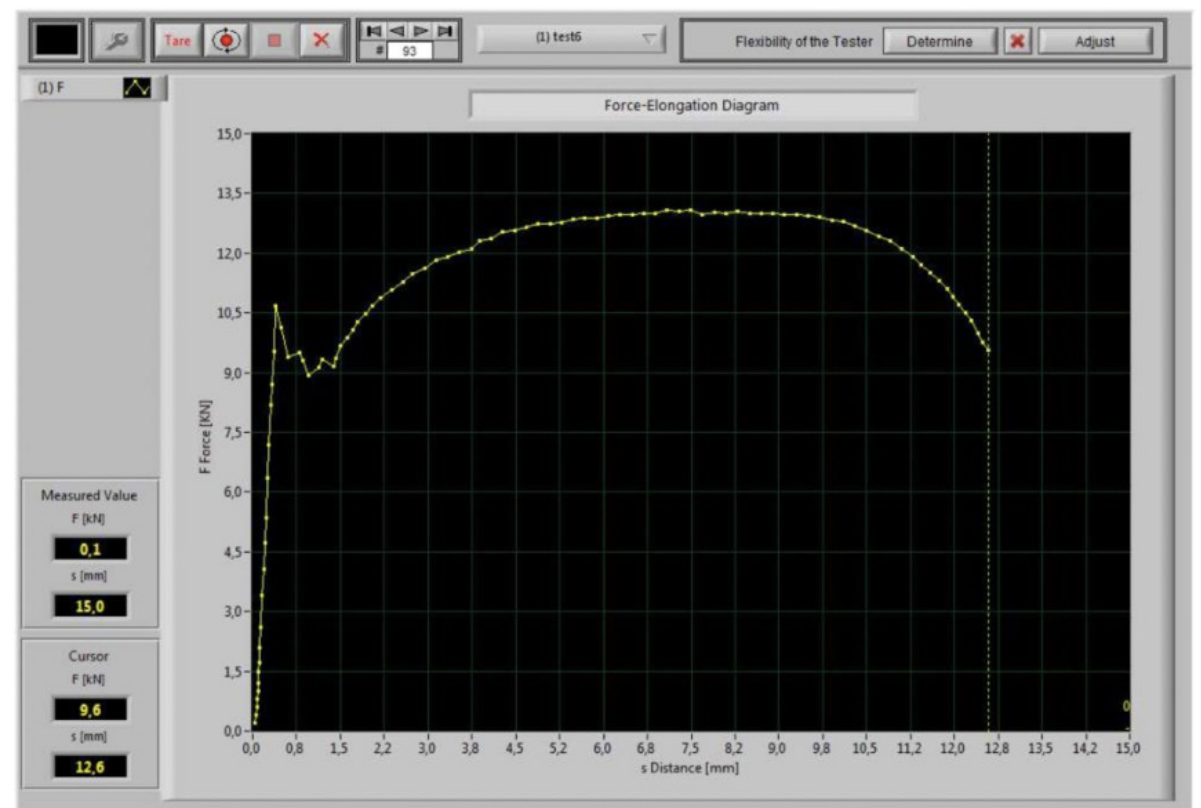

Figure 3: Stress-strain data from WP300.20 GUNT® Hamburg universal material tester 


\subsection{Infrared Thermography}

The test specimens were monitored with the infrared thermography throughout the course of the tensile tests using FLIR ${ }^{\circledR}$ T1030sc thermal camera [14] and analyzed using Researcher IR Max software [15] (Figure 4), to investigate the heat generation associated with the thermoelastic/thermoplastic effects. With the use of thermography, the infrared wavelengths emitted from the test specimen were observed in high-definition thermal images. The rate of energy emitted as thermal radiation is highly dependent on the surface temperature. Small temperature changes in the test specimens generate visible thermal readings. Similar studies have been carried out by [2,16-19].

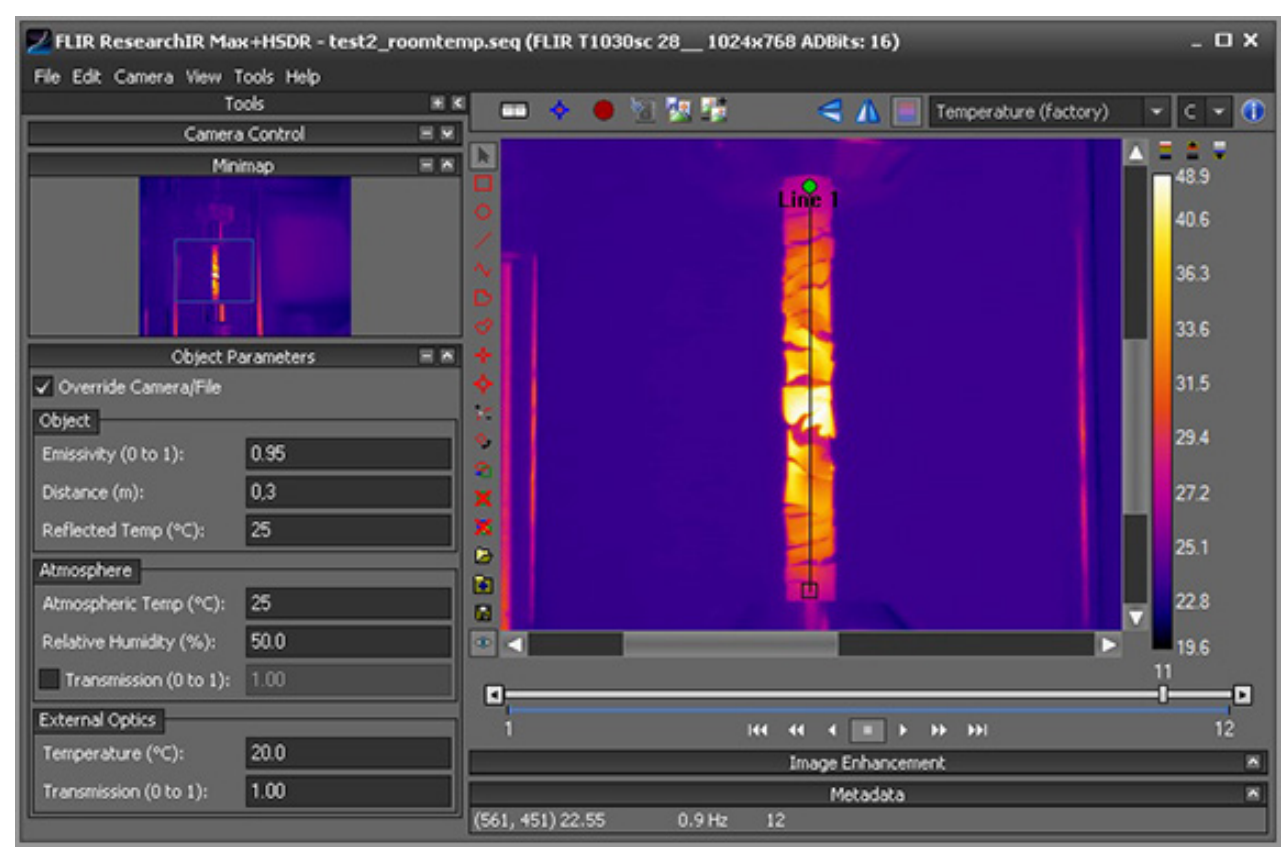

Figure 4: Researcher IR Max software

\subsection{Thermal Image Analysis}

The profile plot of the test specimen (Figure 5) indicates an irregular distribution with substantial temperature drops. This uneven distribution is caused by cracking in the coating of the test specimen, which clearly display the difference in radiation emitted from the white paint and unpolished steel. An estimated temperature distribution was created by only using the peak-values in the profile plot. Figure 6 shows the coated test specimen before and after fracture. The emissivity of the paint was calibrated and found to be 0.95 . 


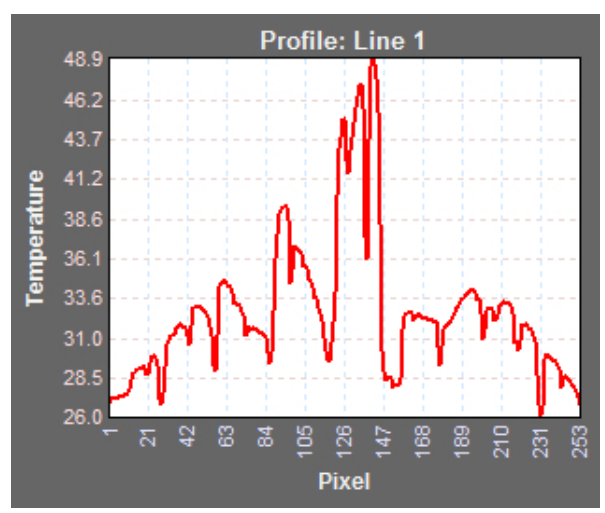

Figure 5: Irregular distribution thermal distribution

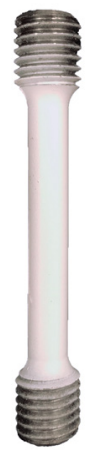

(a) Before

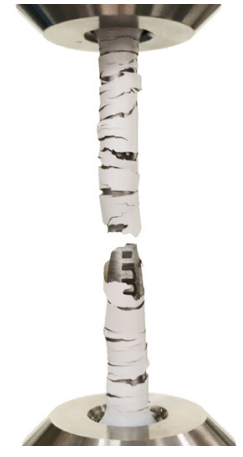

(b) After fracture

Figure 6: DIN 50125 standard steel sample before and after fracture

\subsection{Numerical Analysis}

The numerical analysis was performed in ANSYS ${ }^{\circ}$ Workbench simulation platform. The analysis method selected for the tensile test was Explicit dynamics; a nonlinear approach for structures exposed to short-duration severe loading, large material deformation and material failure [20]. By using this analysis method, the plastic behavior can be observed, with mechanisms i.e. necking and fracture of the test specimen.

The material selected was Carbon Steel Grade 1006, which has the most similar properties as the steel used in the experimental tests. The method of meshing selected for the test specimen was the Patch Conforming Method, which gave a total of 4150 nodes and 19283 elements. The model of the test specimen with meshing is shown in figure $7 \mathrm{~b}$.

The numerical study aim was to simulate the tensile test in the same conditions as done for the experimental tensile tests, by defining a load with velocity (elongation per second) and a total test time of $50 \mathrm{~s}$ in the analysis settings. The study was based on a simulation performed with a displacement of $16 \mathrm{~mm}$, and a defined test time of 0.001 seconds. Figure 8 shows the fixed support and displacement of the test specimen. 


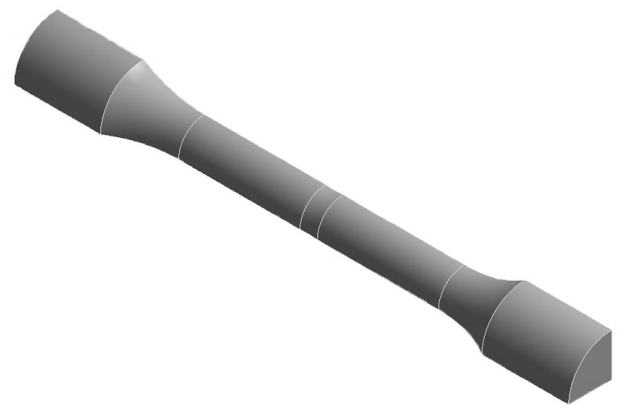

(a) Geometric model

Figure 7: Tensile specimen

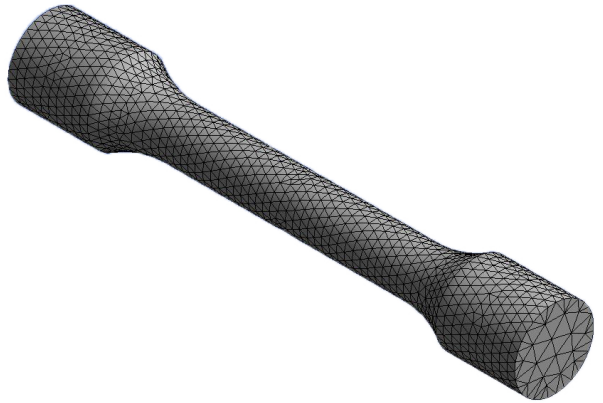

(b) Finite element mesh

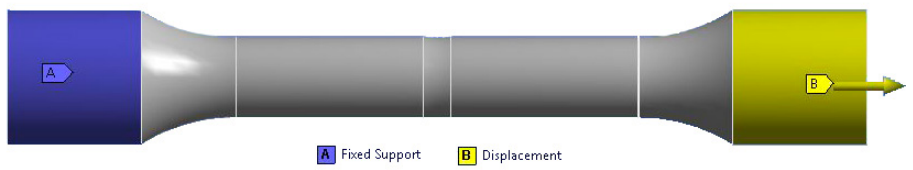

Figure 8: Load and support

The test specimen was solved for equivalent (Von-Mises) Stress, and for temperature by user defined results. Due to the defined test time, the tensile test was simulated with a significant load under adiabatic conditions. The simulation visualizes the stress concentrations and heat generation in the test specimen, which has been analyzed and compared qualitatively with the experimental tests. Figure 9 shows the software-window of the explicit dynamic analysis in ANSYS Workbench.

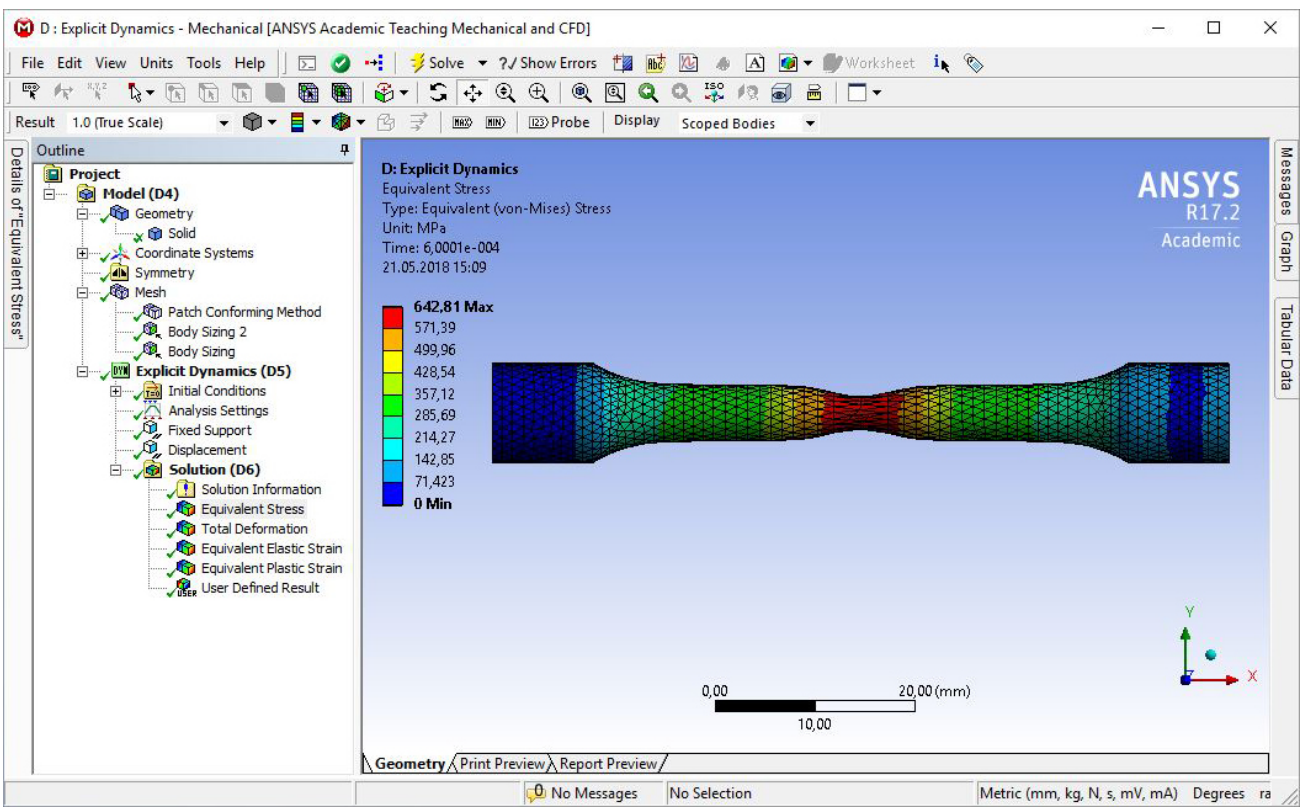

Figure 9: ANSYS $®$ Workbench software-window 


\section{RESULTS AND DISCUSSION}

\subsection{Stress-Strain Analysis}

The average stress-strain diagram obtained from experimental work is shown in figure 10 . Curves indicates an approximately equal tensile behavior for all temperatures, with the region of necking in $-20{ }^{\circ} \mathrm{C}$ as an exception. The average stress-strain behavior indicates a minor increase in both yield- and ultimate stress, with decreasing temperature. The average values for yield stress and ultimate stress are presented in table 1, with the calculated standard deviation. The yield stress exhibited an increase of $26 \mathrm{~N} / \mathrm{mm}^{2}$ whereas the ultimate stress exhibited a total increase of $15 \mathrm{~N} / \mathrm{mm}^{2}$, with a steady increase between $-5{ }^{\circ} \mathrm{C}$ and $-20{ }^{\circ} \mathrm{C}$.

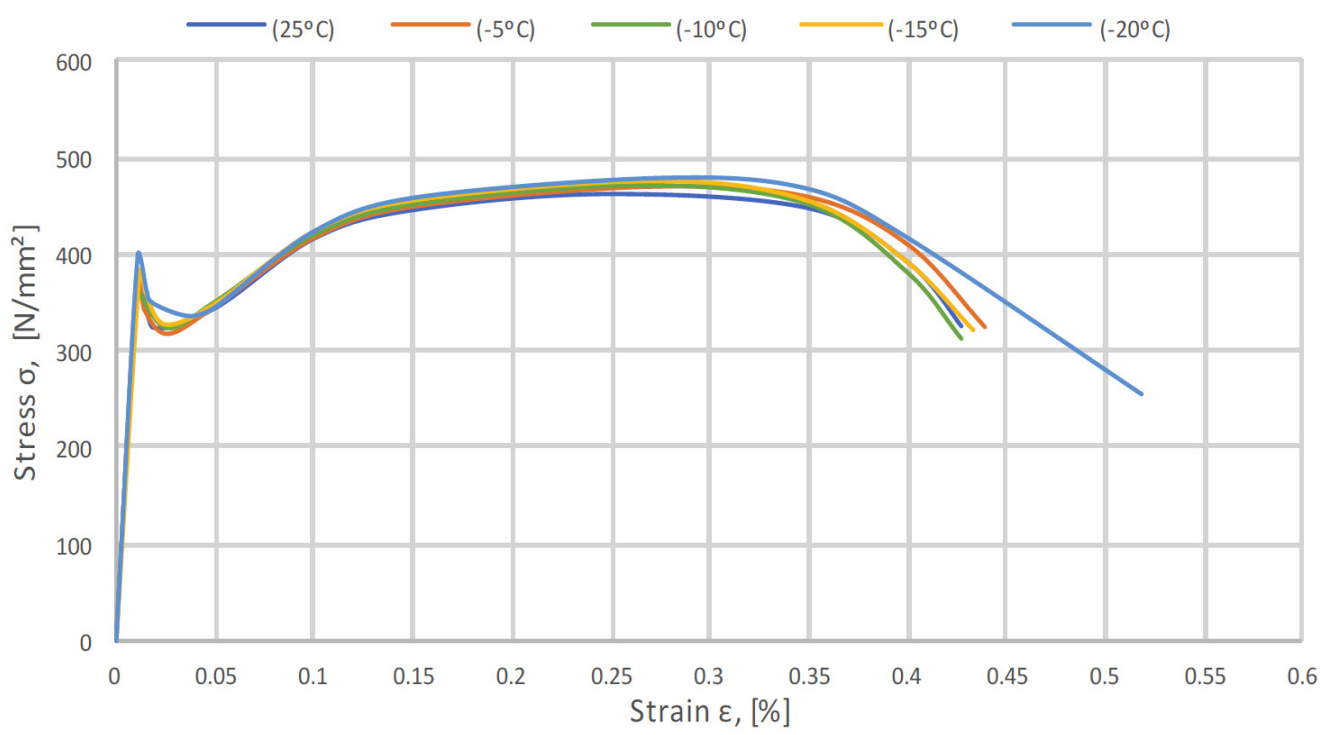

Figure 10: Average stress-strain diagram

Table 1: Average stress values

\begin{tabular}{lll}
\hline & Yield Stress $\left(\mathbf{N} / \mathbf{m m}^{\mathbf{2}}\right)$ & Ultimate Stress $\left(\mathbf{N} / \mathbf{m m}^{\mathbf{2}}\right)$ \\
\hline Test $\left.^{(25}{ }^{\circ} \mathbf{C}\right)$ & $370.29 \pm 10.02$ & $462.28 \pm 5.514$ \\
Test $\left(-\mathbf{5}^{\circ} \mathbf{C}\right)$ & $374.30 \pm 8.07$ & $470.63 \pm 2.62$ \\
Test $\left(-\mathbf{- 1 0}^{\circ} \mathbf{C}\right)$ & $375.26 \pm 3.51$ & $471.29 \pm 2.69$ \\
Test $\left(-\mathbf{1 5}^{\circ} \mathbf{C}\right)$ & $381.80 \pm 4.26$ & $476.17 \pm 4.38$ \\
Test $\left(-20^{\circ} \mathbf{C}\right)$ & $396.54 \pm 5.24$ & $477.37 \pm 1.46$ \\
Increase from $\mathbf{~ 2 5}^{\circ} \mathbf{C}$ to $\mathbf{- 2 0}^{\circ} \mathbf{C}$ & 26.25 & 15.09 \\
\hline
\end{tabular}

\subsection{Thermography Analysis}

The heat generation exhibited in the steel specimens in Figure 11, 12 was not thermally isolated therefore there were thermal loses due to conduction and convection. Nonetheless the thermal images obtained via infrared thermography reflects qualitative visualization of the development of stresses as shown in Figure 11, 12. This shows the mechanical energy entering the test specimen in form of applied stresses is converted into heat due to internal friction. The steel specimen exhibited the same temperature change throughout the specimen in the initial 
phase, as the applied stresses were homogeneous. Following, a temperature gradient developed in the specimen, as a result of the non-homogeneous stress due to the plasticity. The first frame illustrates the steel specimen in the start of the tensile test, right before the stress was applied, indicating an approximately equal temperature as its surroundings. The increase in temperature are noticeable for each frame recorded, with the development of a temperature gradient, until the fracture of the specimen.

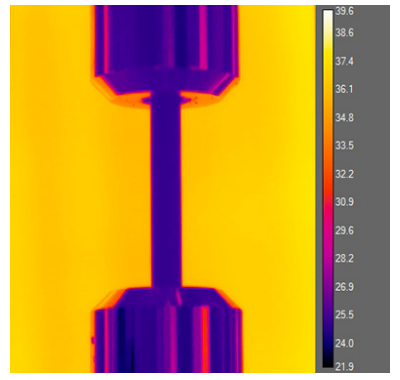

(a) Start

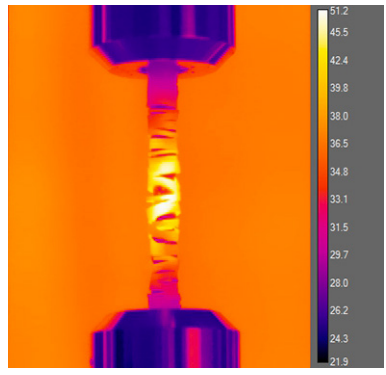

End (45s)

Figure 11: Infrared Thermography of DIN 50125 standard steel sample

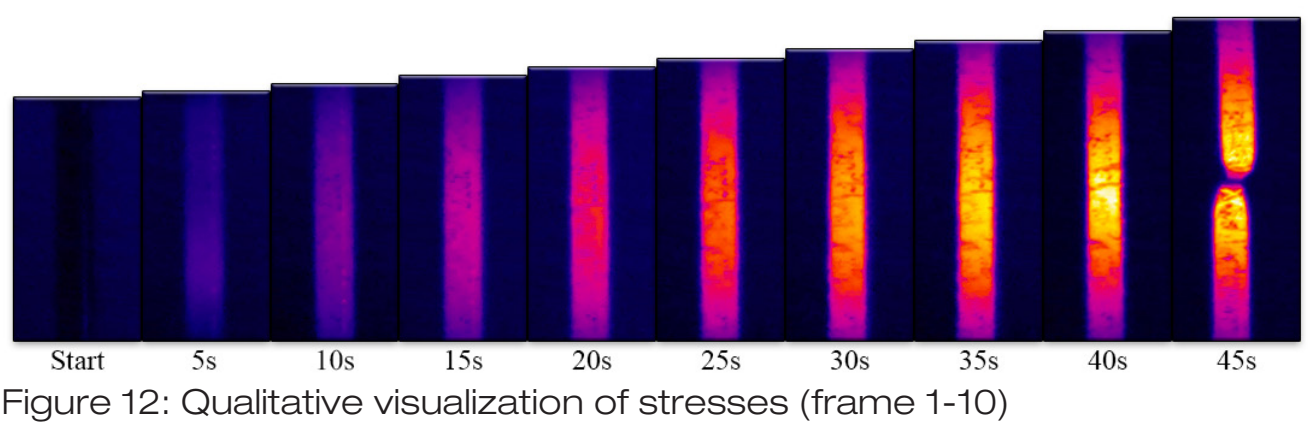

The profile plot for all $\left(25^{\circ} \mathrm{C},-5^{\circ} \mathrm{C},-10{ }^{\circ} \mathrm{C},-15^{\circ} \mathrm{C}\right.$, and $\left.-20{ }^{\circ} \mathrm{C}\right)$ temperatures exhibited the same bell curve distribution as shown in figure $13 \mathrm{~b}$. Table 2 presents the values of temperature change for each defined test temperature. The results of the infrared images and

\begin{tabular}{|c|c|c|c|}
\hline \multicolumn{4}{|c|}{ Table 2: Temperature values } \\
\hline & Start (T1) & End (T2) & $\Delta \mathbf{T}$ \\
\hline \multirow{2}{*}{ Test $\left(25^{\circ} \mathrm{C}\right)$} & 24.218 & 50.3 & 26.083 \\
\hline & 23.059 & 49.2 & 26.141 \\
\hline \multirow[t]{2}{*}{ Test $\left(-5^{\circ} \mathrm{C}\right)$} & -8.614 & 14.292 & 22.906 \\
\hline & -8.937 & 13.84 & 22.777 \\
\hline \multirow{2}{*}{ Test $\left(-10^{\circ} \mathrm{C}\right)$} & -16.827 & 12.104 & 28.931 \\
\hline & -16.554 & 11.279 & 27.832 \\
\hline \multirow[t]{2}{*}{ Test $\left(-15^{\circ} \mathrm{C}\right)$} & -17.356 & 8.077 & 25.433 \\
\hline & -17.428 & 5.015 & 22.442 \\
\hline \multirow{2}{*}{ Test $\left(-20^{\circ} \mathrm{C}\right)$} & -25.623 & 0.486 & 26.109 \\
\hline & -24.888 & 0.215 & 25.102 \\
\hline Average & & & 25.376 \\
\hline
\end{tabular}


associated profile plots indicate an approximately equal heat generation in the steel specimen, for all defined test temperatures. The temperature difference in the specimen varies for each test temperature, but not in a specific pattern. The minimum temperature difference observed was $22.44{ }^{\circ} \mathrm{C}$, and a maximum difference of $28.93{ }^{\circ} \mathrm{C}$.

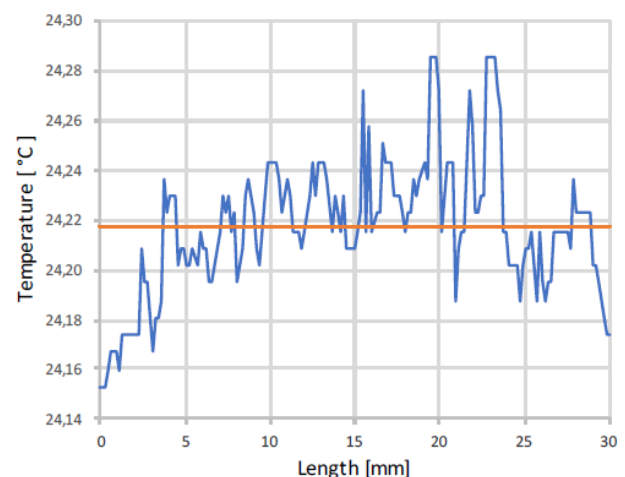

(a) Start

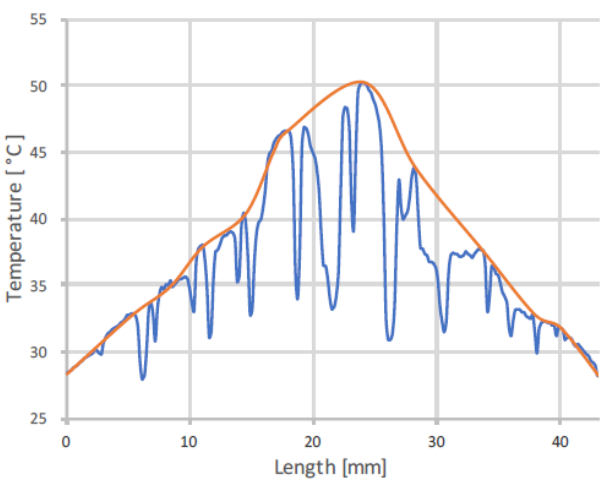

(b) End (45s)

Figure 13: Temperature distribution $\left(25^{\circ} \mathrm{C}\right)$

\subsection{Numerical Analysis}

The simulated tensile test of 1006 Carbon Steel in the explicit dynamics analysis [20] are presented in figure 14. The test specimen exhibited an approximately equal tensile behavior as of that observed from the physical experiments. The initial region indicated evenly distributed stress in the test length, which gradually converted into stress concentrations, followed by necking and final fracture of the specimen. The ultimate stress was observed just before the start of necking, which corresponds with the experimental tensile test. A deviation with the numerical analysis may be interpreted as the early start of necking. Further, the failure mode was relatively equal to the characteristic cup and cone fracture, which was observed for all experimental tensile tests.
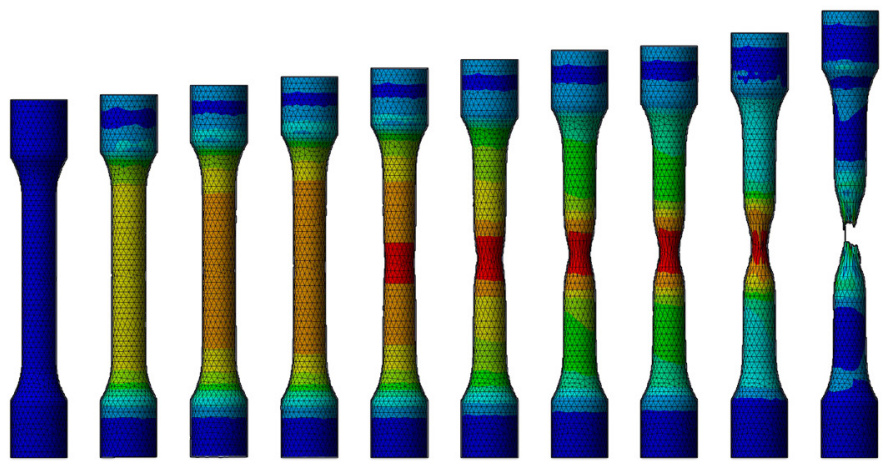

Figure 14: Numerical tensile test 
Figure 15 presents the stress curve generated from the simulated tensile test. The equivalent stress is plotted versus test time and indicate immediate resemblance to the stress-strain curves generated from the experimental tensile test. The stress curve exhibits an equal initial region, with linear response of stress, followed by an upper yield point. The difference can be observed in the region of work hardening, where the stress curve is generated without a lower yield point. This is a result of software limitations, as the material behavior in this region are not possible to simulate in the explicit analysis. The point of ultimate stress can be observed in the stress curve, followed by necking and a decrease in stress. A deviation of the stress curve can be observed in the concluding region, where the specimen fractures. The increase in stress are caused by high calculated stress values in the fracture elements in the specimen. Considering the stress points of interest, upper yield- and ultimate strength, the numerical stress curve corresponds with the generated experimental stress-strain diagrams.

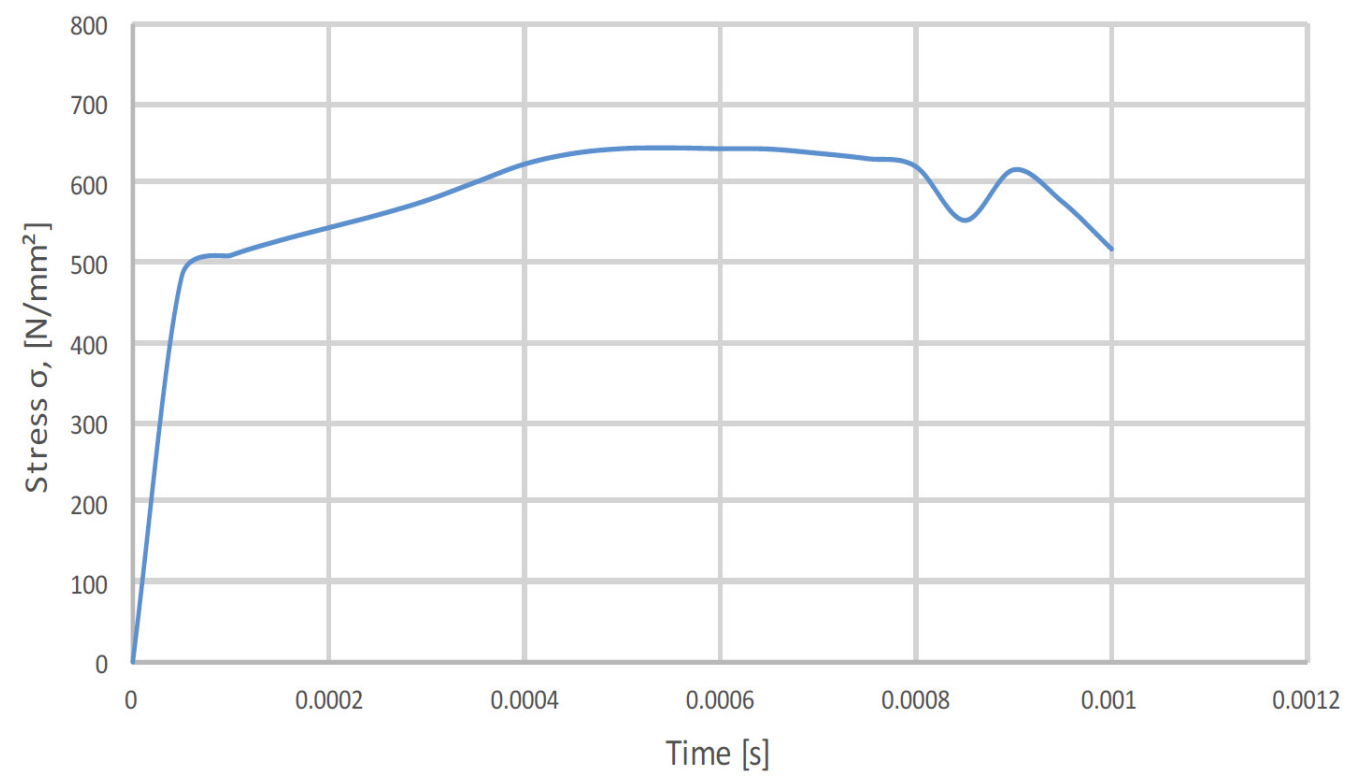

Figure 15: Numerical stress curve

Figure 16 presents the temperature distribution in the test specimen at the time of maximum stress concentrations, before fracture. The diagram is generated by user defined temperature result, which calculated the temperature in the test length of the specimen, based on the equivalent stress values. The numerical temperature distribution presents a similar curve as to the bell curve generated in the profile plots of the experimental tensile tests. That is, a maximum temperature in the middle, which decreases towards the ends of the test specimen. As the tensile test was simulated with adiabatic conditions, no significant time was given for heat transfer to take place. This is visualized by the concentrated heat generation in the middle of the test specimen. 


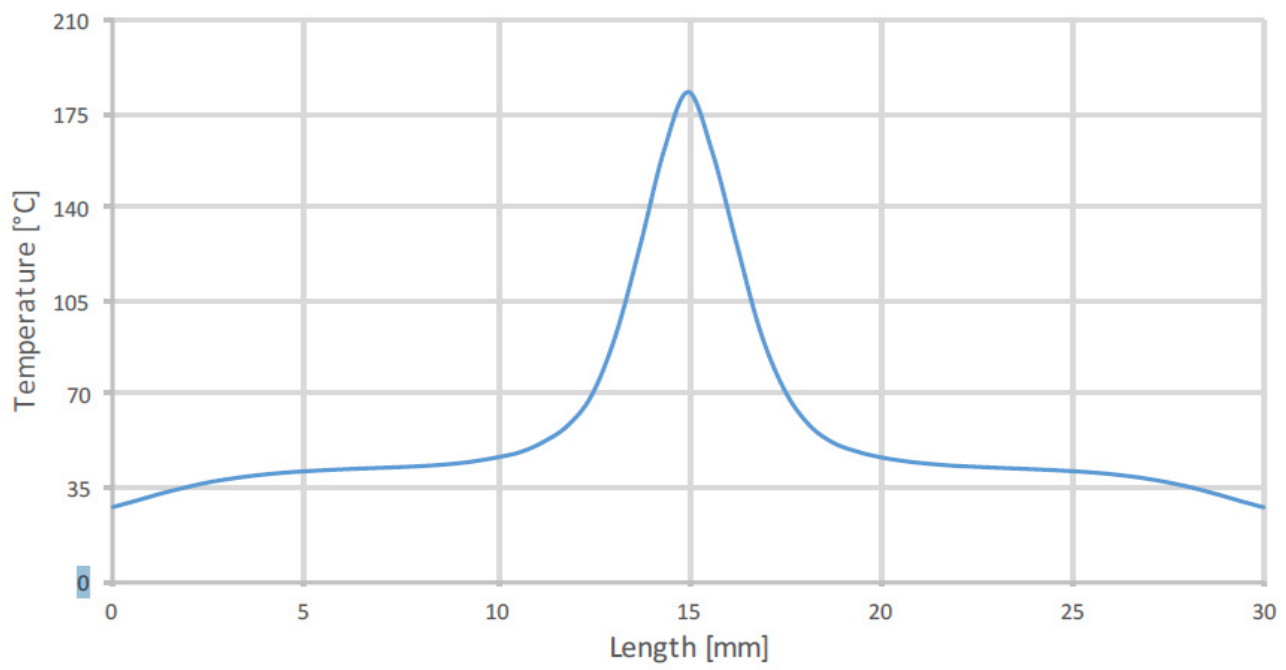

Figure 16: Numerical temperature distribution

\section{CONCLUSION}

Tensile testing is standard test to study stress-strain behavior of materials. The tests are often used to standardize the materials properties. From the generated stress-strain diagrams, a change in material properties could be observed, with decreasing temperature. The yield stress exhibits an increase of $26 \mathrm{~N} / \mathrm{mm}^{2}$, and the ultimate stress an increase of $15 \mathrm{~N} / \mathrm{mm}^{2}$. These results correspond with the general behavior of steel, in the defined temperature range from $25{ }^{\circ} \mathrm{C}$ to $-20{ }^{\circ} \mathrm{C}$.

Heat generation, associated with the thermoelastic effects, could be observed in the steel specimen with thermography. From the generated profile plots, a typical bell curve temperature distribution was developed as a result of the stress concentration in the steel specimens. The heat generation was approximately equal for all defined test temperatures, with an average temperature increase of $25.4{ }^{\circ} \mathrm{C}$.

The study is also an evidence that finite element method is a valid approach for generating graphical measures of mechanical properties and heat generation in the test specimen. The generated stress curve indicated a relatively equal behavior as that observed from the experimental stress-strain curves. Important material properties i.e. the yield point and ultimate strength, could easily be determined from the stress curve. The numerical temperature distribution indicated a similar curve to the bell curve distribution generated from the profile plots, considering the simulation conditions. The accuracy of the explicit solution could be verified only via qualitatively comparison with physical experiments.

\section{REFERENCES}

[1] M. Gedeon, "Stress-strain concepts," Materion Brush Performance Alloys, 2012.

[2] Khawaja, Hassan Abbas; Rashid, Taimur; Eiksund, Oddmar; Brodal, Eivind; Edvardsen, Kåre. Multiphysics Simulation of Infrared Signature of an Ice Cube. The International Journal of Multiphysics, 2016, 10(3), p. 291-302. 
[3] Rogalski, A., Infrared Detectors, Second Edition. 2010: CRC Press

[4] Moatamedi, Mojtaba; Khawaja, Hassan. Finite Element Analysis.2018 CRC Press

[5] Myrli, O; Khawaja, H. Fluid-Structure Interaction (FSI) Modelling of Aquaculture Net Cage. The International Journal of Multiphysics, 2019, 13(1), p. 97 - 111.

[6] Mughal, U; Khawaja, H; Moatamedi, M. Finite element analysis of human femur bone. The International Journal of Multiphysics, 2015, 9(2), p. $101-108$.

[7] Khawaja, H. Application of a 2-D approximation technique for solving stress analyses problem in FEM. The International Journal of Multiphysics, 2015, 9(4), p. 317 - 324.

[8] Khawaja, H; Khalid, P. Validation of normal and frictional contact models of spherical bodies by FEM analysis. The International Journal of Multiphysics, 2010, 4(2), p. 175 -185 .

[9] Khawaja, H; Raouf, I; Khalid, P; Scherer, A. Optimization of elastomeric microfluidic valve dimensions using nonlinear finite element methods. The International Journal of Multiphysics, 2009, 3(2), p. 187 - 200.

[10] Ju Feng Special Steel Co., Ltd. Available: https://www.jfssteel.com/en/steelDetail/DIN-9SMn28/DIN-9SMn28 html [Accessed 5-06-2019]

[11] ANSYS Workbench User's Guide, ANSYS, Inc., 2009

[12] Engineering simulation platform. [Online]. Available: https://www.ansys.com/products/Platform

[13] GUNT® Hamburg Universal material tester. [Online]. Available: https://www.gunt.de/en/products/engineering-mechanics-and-engineeringdesign/testing-of materials/tensile-compression-bending-and-hardnesstesting/materials-testing 20kn/020.30000/wp300/glct-1:pa-148:ca-34:pr-1540 [Accessed 5-06-2019]

[14] FLIR Systems, Inc. Available: http://www.flir.eu/aboutFLIR/ [Accessed 5-06-2019]

[15] Research IR user's guide. Available: https://assets.techedu.com/assets/1/26/FLIR_ResearchIR_User_Manual1.pdf [Accessed 5-06-2019]

[16] Rashid, Taimur; Khawaja, Hassan Abbas; Edvardsen, Kåre. Determination of Thermal Properties of Fresh Water and Sea Water Ice using Multiphysics Analysis. The International Journal of Multiphysics, 2016, 10(3), p.277-291.

[17] Ahmad, Tanveer; Rashid, Taimur; Khawaja, Hassan Abbas; Moatamedi, Mojtaba. Study of the required thermal insulation (IREQ) of clothing using infrared imaging. The International Journal of Multiphysics, 2017; 11(4), p.413-426.

[18] Rashid, Taimur; Khawaja, Hassan; Edvardsen, Kåre. Measuring Thickness of Marine Ice Using IR Thermography. Cold Regions Science and Technology, 2019, 158, p.221-229

[19] Khawaja, H; Ahmad, T. Review of Low-Temperature Crack (LTC) Developments in Asphalt Pavements. The International Journal of Multiphysics, 2018, 12(2), p. 169 187.

[20] (2011) Explicit dynamics. [Online]. Available: https://www.ansys.com/-/media/ansys/ corporate/resourcelibrary/brochure/ansys-explicit-dynamics-brochure-140.pdf 